\title{
Correlation of Serum Homocysteine Levels with the Severity of Coronary Artery Disease
}

\author{
Vijetha Shenoy • Veena Mehendale • \\ Krishnananda Prabhu • Ranjan Shetty • \\ Pragna Rao
}

Received: 31 May 2013/Accepted: 19 August 2013/Published online: 31 August 2013

(C) Association of Clinical Biochemists of India 2013

\begin{abstract}
Coronary artery disease (CAD) has become the most common cause of mortality in the entire world. Homocysteine is implicated as an early atherosclerotic promoter. We studied the relationship between levels of serum homocysteine with severity of coronary artery disease. Total of 70 subjects who scheduled for coronary angiogram consented to participate in this study. In all the patients Gensini scoring system was used to assess the severity of CAD. Venous samples were taken from the patients in fasting state before angiography. Homocysteine levels in patients were measured by enzyme linked immunosorbant method and were compared with respective Genseni scores of participants. Fasting serum homocysteine levels in CAD patients were significantly higher than patients without coronary artery disease $(p<0.001)$. Also Homocyseine levels correlated significantly with increasing severity of CAD $(p<0.001)$. Serum homocysteine levels correlated well with the severity of CAD.
\end{abstract}

Keywords Coronary artery disease (CAD) . Homocysteine $\cdot$ Gensini scoring system

\footnotetext{
V. Shenoy · K. Prabhu ( $₫) \cdot$ P. Rao

Department of Biochemistry, Kasturba Medical College,

Manipal University, Manipal, India

e-mail: krishnakunj2000@yahoo.com

V. Mehendale

Department of Applied Nutrition, Dietics Welcome Group

School of Hotel Management, Manipal University, Manipal, India

R. Shetty

Department of Cardiology, Kasturba Medical College, Manipal

University, Manipal, India
}

\section{Introduction}

Coronary artery disease (CAD) has become a major health problem and main contributor to mortality in the entire world as well in our country India. India is in epidemiological transition. The emerging threat of non-communicable diseases is a matter of concern in addition to the burden of endemic infections. Previously, CAD was considered to be a result of an urban life style; however, recently published studies have indicated that $\mathrm{CAD}$ is also on the rise in rural areas $[1,2]$. According to the World Heart Federation, $35 \%$ of all CVD deaths in India occur in those aged 35-64 years [3]. 90-95\% of all cases and deaths are due to CAD [4]. Approximately, one-sixth of world's population lives in India and CAD remains the highest cause of mortality in India [5]. Coronary artery disease is the narrowing or blockage of the arteries and vessels that supply oxygen and nutrients to heart. The severity of CAD is classified as single vessel, double vessels, triple vessels disease and using Gensini scoring system.

Most of the CADs are explained in the presence of traditional risk factors like hyperlipidemia, smoking, hypertension, and diabetes mellitus, those 15-20\% of CAD have no identifiable risk factors and therefore they miss the opportunity for primary prevention [6]. However, despite aggressive control of risk factors in the general population, it is not possible to prevent progression of CAD in all patients. Homocysteine has been recognized as early in 1990s as a risk factor for the presence of atherosclerotic vascular disease and hypercoagulability states [7, 8]. Homocysteine has emerged as a significant marker of vascular disease, especially in patients of Asian origin [9]. Increasing age, male sex, smoking, coffee consumption, high blood pressure, unfavorable lipid profile, high 
creatinine and faulty diet are among the factors associated with increased homocysteine levels; physical activity, moderate alcohol consumption, a good folate and vitamin B-12 status are associated with lower homocysteine levels [10]. Strict vegetarians are often at risk for hyperhomocysteinemia due to low plasma B12 levels [11, 12]. Coffee consumption seems to be linked with moderate elevations in homocysteine [13]. As with nearly every other cardiovascular risk factor, smoking cigarettes is linked with elevated levels of homocysteine [14, 15]. Numerous epidemiological studies have shown homocysteine levels correlate inversely more closely with plasma folate levels and less so with vitamin B12 and B6 levels. It has been proved that intake of daily folic acid supplements reduces the levels of homocysteine which in turn declines the morbidity of CAD [16, 17].

Several studies have elucidated an association of hyperhomocysteinemia with vascular disease independent of the conventional factors [18-20]. So, this study was carried out to assess the homocysteine levels in CAD patients and to compare it with the severity of CAD.

\section{Materials and Methods}

\section{Study Population}

70 patients undergoing coronary angiography at Kasturba Hospital, Manipal University, Manipal, Karnataka, India, a tertiary care center between August 2012 to November 2012, consented to participate in this study.

Coronary artery disease was defined as any degree of stenosis in the major coronary arteries. CAD is graded according to the number of involved vessels: non CAD, single vessel disease (SVD), double vessels disease (DVD), triple vessels disease (TVD).

\section{Ethical Statement}

Ethical clearance was obtained from institutional ethical committee prior to the data collection

\section{Selection of Participants}

Inclusion criteria:

Patients undergoing coronary angiogram in the age group of 31-65 years.

Exclusion criteria:

- Patients who have been taking vitamin supplements since 3 months

- Patients suffering from renal diseases, thyroid problems, pregnant women, psoariasis, psychological disorders, inflammatory bowel disease, epilepsy, cancer, smokers

- Patients $<31$ and $>65$ years were excluded from the study.

\section{Assessment of Severity of $C A D$}

Severity of CAD signifies the percentage of blockage present in the coronary arteries. It was scored based on the percentage of blockage present in the three coronary arteries i.e. Left anterior descending artery(LAD), Left circumflex artery (LCx) and Right coronary artery and their branches and this is called as Gensini Score. It is a scoring system for evaluating collateral circulation of the coronary arteries and it assesses the extent of blockage.

\section{Sample}

After an overnight fast $5 \mathrm{ml}$ of venous blood is drawn in red vacutainer prior to the coronary angiography. Serum was separated and stored at $-20{ }^{\circ} \mathrm{C}$ until measurement of homocysteine. Homocysteine was measured with an enzyme linked immunosorbant (ELISA) method. The upper limit of normal provided by company was $15 \mu \mathrm{mol} / 1$

\section{Statistical Analysis}

The data collected was studied and analyzed using the SPSS software16.0 version to result in conclusion of the study. Independent student $t$ test, correlation used wherever appropriate. $p<0.05$ was considered to indicate statistical significance.

\section{Result}

Demographic Profile

\section{Gender}

It is found that out of 51 male patients, 42 (82\%) had coronary artery disease and remaining $9(18 \%)$ had normal coronaries and out of 19 females, 9 (47\%) had coronary artery disease and remaining $10(53 \%)$ had normal coronaries (Table 1).

Age

Majority of CAD patients $38(73 \%)$ fall in the age group of 51-65 years while most of the non CAD patients 14 (27\%) fall in the age group of 51-65 years. About 10 $(67 \%)$ CAD patients and $5(33 \%)$ were falling in the age 
Table 1 Demographic characteristics of the study subjects

\begin{tabular}{|c|c|c|c|c|}
\hline & \multicolumn{2}{|l|}{ CAD } & \multicolumn{2}{|l|}{ Non CAD } \\
\hline & $\begin{array}{l}\text { Frequency } \\
\mathrm{N}\end{array}$ & $\begin{array}{l}\text { Percentage } \\
\%\end{array}$ & $\begin{array}{l}\text { Frequency } \\
\mathrm{n}\end{array}$ & $\begin{array}{l}\text { Percentage } \\
\%\end{array}$ \\
\hline \multicolumn{5}{|l|}{ Gender } \\
\hline Males & 42 & 82 & 9 & 18 \\
\hline Females & 9 & 47 & 10 & 53 \\
\hline \multicolumn{5}{|l|}{ Age } \\
\hline $30-40$ years & 3 & 100 & 0 & 0 \\
\hline $41-50$ years & 10 & 67 & 5 & 33 \\
\hline $51-65$ years & 38 & 73 & 14 & 27 \\
\hline
\end{tabular}

group of 41-50. Only $3(100 \%)$ of the CAD patients were falling under the age group of 30-40 years. Mean age of CAD patients was $54 \pm 7.47$ (Table 1).

\section{Medical History}

In the study group 25 of CAD patients and 8 of the non CAD were hypertensives. About 20 of CAD patients and 5 of non CAD patients were know diabetics (Table 2).

\section{Life Style Habits}

A life style habit includes alcohol consumption, coffee consumption and type of diet consumed. Frequency and percentage of all these habits is depicted in the Table 3, 4, 5 .

\section{Biochemical Parameters}

Biochemical parameters like Fasting blood sugar levels, lipid profile results were compared between CAD and non CAD subjects (Table 6).

Table 2 Medical history of patients

\begin{tabular}{llllll}
\hline & \multicolumn{2}{l}{$\mathrm{CAD}$} & & \multicolumn{2}{l}{ Non CAD } \\
\cline { 6 - 6 } \cline { 5 - 6 } & $\mathrm{n}$ & $\%$ & & $\mathrm{n}$ & $\%$ \\
\hline Medical history & & & & \\
Hypertensive & 25 & 75 & & 25 \\
Diabetic & 20 & 80 & & 5 & 20 \\
\hline
\end{tabular}

Table 3 Alcohol consumption among study group

\begin{tabular}{llllll}
\hline & \multicolumn{2}{l}{ CAD } & & \multicolumn{2}{c}{ Non CAD } \\
\cline { 6 - 6 } \cline { 5 - 6 } & $\mathrm{n}$ & $\%$ & & $\mathrm{n}$ & $\%$ \\
\hline Alcohol consumption & & & & \\
Non consumer & 28 & 67 & 14 & 33 \\
Consumer & 23 & 82 & 5 & 18 \\
\hline
\end{tabular}

Table 4 Coffee consumption among patients

\begin{tabular}{llllll}
\hline & CAD & & & Non CAD & \\
\cline { 5 - 6 } \cline { 5 - 6 } & $\mathrm{n}$ & $\%$ & & $\mathrm{n}$ & $\%$ \\
\hline Coffee consumption & & & & \\
Non consumer & 35 & 76 & 11 & 24 \\
Consumer & 16 & 66 & 8 & 34 \\
\hline
\end{tabular}

Table 5 Type of diet followed among patients

\begin{tabular}{lrrrr}
\hline & CAD & & Non CAD & \\
& $\mathrm{n}$ & $\%$ & $\mathrm{n}$ & $\%$ \\
\hline Type of diet & & & & \\
Non vegetarians & 44 & 73 & 16 & 27 \\
Lacto vegetarians & 7 & 70 & 3 & 30 \\
\hline
\end{tabular}

Confounding Variables

The mean homocysteine levels among lacto vegetarians were higher when compared to the non-vegetarians among CAD patients but it was not statistically significant. There was no significant statistical difference in the mean homocysteine levels among diabetics and non diabetics, hypertensives and non hypertensives, alcohol consumers and alcohol non consumers, coffee consumers and coffee non consumers (Table 7).

Angiogram profile reveled maximum patients had single vessel disease (Fig. 1).

There was a significant increase in serum homocysteine levels in CAD patients as compared to that of controls $(p<0.001)$ (Table 8). Fasting homocysteine levels significantly correlated with gensini score of patients $(p<0.001)$ (Fig. 2) indicating a possible role for this parameter in grading and risk stratification of CAD patients.

\section{Discussion and Conclusion}

The elevated homocysteine was being considered as an independent risk factor for cardiovascular disease by the early 1990s. A key metaanalysis published in 1995 by JAMA in which 27 studies involving over 4,000 subjects concluded that homocysteine was an independent risk factor for cardiovascular disease and it estimated that $10 \%$ of population's CVD risk is attributed to the elevated levels of homocysteine [21]. There is strong evidence that oxidation is part of mechanism attributed to increased homocysteine and atherosclerosis. The most common and plausible mechanism for increased risk of CAD are endothelial dysfunction thought to occur primarily from 
Table 6 Correlation of biochemical parameters among CAD and Non CAD group

* Independent $\mathrm{t}$ test $S E M$ standard error of mean, $N S$ not significant

\begin{tabular}{lccl}
\hline & $\begin{array}{l}\text { Mean } \pm \text { SEM in } \\
\text { CAD subjects }\end{array}$ & $\begin{array}{l}\text { Mean } \pm \text { SEM in } \\
\text { non CAD subjects }\end{array}$ & $p$ value* \\
\hline Fasting blood sugar & $129.57 \pm 7.23$ & $114.32 \pm 6.25$ & $0.2^{\mathrm{NS}}$ \\
Total cholesterol & $165.65 \pm 5.91$ & $153.11 \pm 10.17$ & $0.28^{\mathrm{NS}}$ \\
Triglycerides & $152.27 \pm 15$ & $122.32 \pm 12.2$ & $0.24^{\mathrm{NS}}$ \\
HDL cholesterol & $36 \pm 1.18$ & $36.32 \pm 2.45$ & $0.89^{\mathrm{NS}}$ \\
LDL cholesterol & $99.88 \pm 5.44$ & $91.47 \pm 9.1$ & $0.4^{\mathrm{NS}}$ \\
\hline
\end{tabular}

Table 7 Comparison of serum homocysteine levels with the confounding factors

\begin{tabular}{|c|c|c|c|c|c|c|}
\hline & \multicolumn{6}{|c|}{ Fasting homocysteine $(\mu \mathrm{mol} / \mathrm{l})$} \\
\hline & \multicolumn{3}{|l|}{ CAD cases } & \multicolumn{3}{|c|}{ Non CAD cases } \\
\hline & Mean \pm SD & $\mathrm{t}$ value & $p$ value & Mean $\pm \mathrm{SD}$ & $\mathrm{t}$ value & $p$ value \\
\hline \multicolumn{7}{|l|}{ Gender } \\
\hline Males & $23.24 \pm 5.65$ & -0.289 & $0.774^{\mathrm{NS}}$ & $16 \pm 6.57$ & 1.59 & $0.13^{\mathrm{NS}}$ \\
\hline Females & $23.89 \pm 8.19$ & & & $11.6 \pm 5.48$ & & \\
\hline \multicolumn{7}{|l|}{ Type of diet } \\
\hline Lactovegetarians & $27.00 \pm 4.69$ & -1.74 & $0.088^{\mathrm{NS}}$ & $14 \pm 5.29$ & 0.092 & $0.927^{\mathrm{NS}}$ \\
\hline Nonvegetarians & $22.77 \pm 6.11$ & & & $13.62 \pm 6.59$ & & \\
\hline Diabetics & $22.95 \pm 4.91$ & 0.38 & $0.708^{\mathrm{NS}}$ & $13.6 \pm 4.72$ & 0.034 & $0.97^{\mathrm{NS}}$ \\
\hline Nondiabetics & $23.61 \pm 6.79$ & & & $13.71 \pm 6.90$ & & \\
\hline Hypertensives & $24.04 \pm 5.50$ & -0.8 & $0.43^{\mathrm{NS}}$ & $11.88 \pm 4.32$ & 1.08 & $<0.001 * *$ \\
\hline Nonhypertensives & $22.69 \pm 6.63$ & & & $15 \pm 7.29$ & & \\
\hline Alcohol consumers & $23.13 \pm 6.56$ & 0.235 & $0.82^{\mathrm{NS}}$ & $17.2 \pm 8.07$ & -1.402 & $0.18^{\mathrm{NS}}$ \\
\hline Non-alcoholics & $23.54 \pm 5.77$ & & & $12.62 \pm 5.45$ & & \\
\hline Coffee consumers & $22.94 \pm 7.56$ & 0.327 & $0.745^{\mathrm{NS}}$ & $12.5 \pm 6.02$ & 0.692 & $0.5^{\mathrm{NS}}$ \\
\hline Non consumers & $23.54 \pm 5.38$ & & & $14.55 \pm 6.59$ & & \\
\hline
\end{tabular}

NS not significant

** Significant

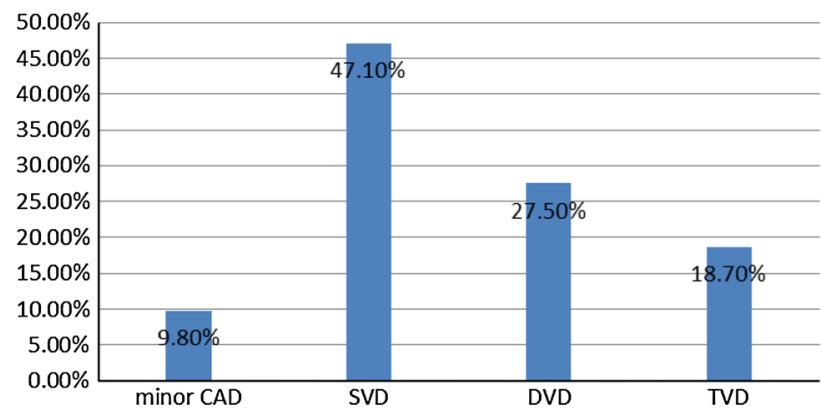

Fig. 1 Angiogram profile of CAD patients ( $S V D$ single vessel disease, $D V D$ double vessel disease, $T V D$ triple vessel disease)

oxidative stress. Studies have shown that homocysteine suppresses the vasodilator nitric oxide by increasing the levels of asymmetric dimethylarginine (ADMA), a strong inhibitor of nitric oxide synthase (eNOS). If this mechanism is true, this could certainly account for dramatic changes in vascular endothelial compliance and platelet coagulation changes that promote cardiovascular disease. In the various in vitro studies, homocysteine was proved to trigger proliferation of vascular smooth muscle cells. The arterial lumen space will be narrower by increasing proliferation of vascular smooth typically considered as deleterious effect for CAD. It also has role in increasing the activity of HMG Co A reductase which in turn increases cholesterol synthesis. An increased cholesterol levels promotes atherosclerosis and risk factor for CAD [22-24].

All most all prospective and retrospective studies have confirmed that high homocysteine is an independent risk factor for CAD. Some studies demonstrated that hyperhomocysteinemia can predispose patients to CAD in patients with hypertension, smoking and hypercholesterolemia [25].

In this correlation study, there were no significant differences in levels of fasting blood sugar and lipid profile 
Table 8 Comparison of serum homocysteine levels among CAD and Non CAD patients

\begin{tabular}{lllll}
\hline & $\begin{array}{l}\text { CAD } \\
\text { patients } \\
\text { Mean } \pm \text { SD }\end{array}$ & $\begin{array}{l}\text { Non CAD } \\
\text { patients } \\
\text { Mean } \pm \text { SD }\end{array}$ & $t$ value & $p$ value** \\
\hline $\begin{array}{l}\text { Fasting } \\
\text { homocysteine }\end{array}$ & $23.35 \pm 6.08$ & $13.68 \pm 6.27$ & -5.86 & $<0.001$ \\
\hline
\end{tabular}

** Independent student $t$ test

Significant

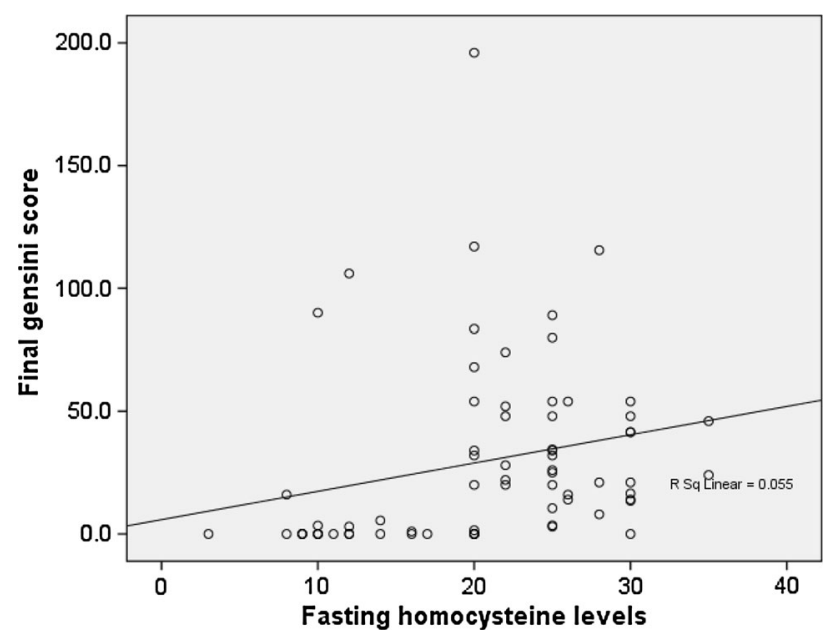

Fig. 2 Correlation of fasting serum homocysteine levels with respective Gensini scores $(r=0.443 ; p$ value $<0.001 * *)$

levels between CAD group and non CAD group. Comparison of fasting serum homocysteine levels with the confounding variables like sex, type of diet, life style habits like alcohol consumers, coffee consumers, medical problems like diabetes and hypertension did not show any statistically significant difference between CAD and non CAD study groups. Serum levels of homocysteine were significantly higher in CAD than in non CAD subjects. Increased serum homocysteine levels positively correlated with severity of CAD (graded using Gensini scoring system).

In conclusion, the serum homocysteine is definitely an independent risk factor for coronary artery disease. There is a strong correlation between severity of CAD and serum homocysteine levels.

\section{Limitation of the Study}

The major determinants of serum homocysteine levels are vitamin B and folic acid intake. In this study we have not measured the levels of vitamin B and folate levels.
Acknowledgement We are grateful to our Dean, Kasturba Medical College, Manipal University, Manipal for providing support to conduct study.

\section{References}

1. Patil SS, Joshi R, Gupta G, Reddy MV, Pai M, Kalantri SP. Risk factors for acute myocardial infarction in a rural population of central India: a hospital-based case control study. Natl Med J India. 2004;17:189-94.

2. Goel PK, Bharti BB, Pandey CM, Singh U, Tewari S, Kapoor A, et al. A tertiary care hospital-based study of conventional risk factors including lipid profile in proven coronary artery disease. Ind Heart J. 2003;55:234-40.

3. Fuster V, Voute J. MDGs: chronic diseases are not on the agenda. Lancet. 2005;366(9496):1512-4.

4. Upadhyaya RP. An overview of the burden of non-communicable diseases in India. Iran J Public Health. 2012;41(3):1-8.

5. Goyal A, Yusuf S. The burden of cardiovascular disease in the Indian subcontinent. Indian J Med Res. 2006;124(3):235-44.

6. Smith SC Jr. Current and future directions of cardiovascular risk prediction. Am J Cardiol. 2006;97:28A-32A.

7. Mallinow MR. Hyperhomocysteinemia A common and easily reversible risk factor for occlusive atherosclerosis. Circulation. 1990;81(6):2004-6.

8. Abraham R, Joseph John M, Calton R, Dhanoa J. Raised serum homocysteine levels in patients of coronary artery disease and the effect of vitamin B12 and folate on its concentration. Indian J Clin Biochem. 2006;21(1):95-100.

9. Chambers J, Obeid O, Refsum H, et al. Plasma homocysteine concentrations and risk of coronary heart disease in UK Indian Asian and European men. Lancet. 2000;355(9203):523-7.

10. Refsum H. The Hordaland Homocysteine Study: a communitybased study of homocysteine, its determinants, and associations with disease. J Nutr. 2006;136(6 Suppl):1731S-40S.

11. Herrmann W, Schorr H, Obeid R, Geisel J. Vitamin B12 status particularly holotranscobalamin II and methylmalonic acid concentrations, and hyperhomocysteinemia in vegetarians. Am J Clin Nutr. 2003;78(1):131-6.

12. Bissoli L, Di Francesco V, Ballarin A, Mandragona R, Trespidi R, Brocco G, et al. Effect of vegetarian diet on homocysteine levels. Ann Nutr Metab. 2002;46(2):73-79.

13. Verhoef P, Pasman W, Vleit T, Urgert R, Katan M. Contribution of caffeine to the homocysteine-raising effect of coffee: a randomized controlled trial in humans. Am J Clin Nutr. 2002; 76(6):1244-8.

14. Tsiaras EM. Influence of smoking on predictors of vascular disease. Angiology. 2003;54(5):507-30.

15. Bazzano LA, He J, Muntner P, Vupputuri S, Whelton P. Relationship between cigarette smoking and novel risk factors for cardiovascular disease in the United States. Ann Intern Med. 2003;138(11):891-7.

16. Mizrahi EH, Jacobsen DW, Debanne SM, Traore F, Lerner AJ, Friedland RP, Petot GJ. Plasma total homocysteine levels, dietary vitamin $\mathrm{B} 6$ and folate intake in $\mathrm{AD}$ and healthy aging. $\mathrm{J}$ Nutr Health Aging. 2003;7(3):160-5.

17. Ward M. Homocysteine, folate and cardiovascular disease. Int $\mathbf{J}$ Vitam Nutr Res. 2001;71(3):173-8.

18. Ueland PM, Refsum H, Beresford SA, Vollset SE. The controversy over homocysteine and cardiovascular risk. Am J Clin Nutr. 2000;72(2):324-32.

19. Stampfer MJ, Malinow MR. Can lowering homocysteine levels reduce cardiovascular risk? N Engl J Med. 1995;332:328-9. 
20. Chai H, Chen Y, Chung S, Tsai T, Yong C, Chen H, et al. Value and level of plasma homocysteine in patients with angina pectoris undergoing coronary angiographic study. Int Heart J. 2011;52: 280-5.

21. Nygard O, Vollset SE, Refsum H, et al. Total plasma homocysteine and cardiovascular risk profile: the Hordaland Homocysteine Study. JAMA. 1995;274:1526-33.

22. Bilsborough W, Green DJ, Mamotte CDS, van Bockxmeer FM, O'Driscoll GJ, Taylor RR. Endothelial nitric oxide synthase gene polymorphism, homocysteine, cholesterol and vascular endothelial function. Atherosclerosis. 2003;169(1):131-8.
23. Kanani PM, Sinkey CA, Browning RL, Allaman M, Knapp HR, Haynes WG. Role of oxidant stress in endothelial dysfunction produced by experimental hyperhomocysteinemia in humans. Circulation. 1999;100(11):1161-8.

24. Cavalca V, Cighetti G, Bamonti F, Loaldi A, Bortone L, et al. Oxidative stress and homocysteine in coronary artery disease. Clin Chem. 2001;47(5):887-92.

25. Mirdamadi A, Farzamnia H, Varzandeh P, Almasi N, Arasteh M. Association between serum homocysteine concentration with coronary artery disease in Iranian patients. ARYA Atheroscler. 2011;7(2):63-7. 